\title{
Section Editor's Introduction
}

Econometric theory and computing power have long since passed the point when an article could provide all the details necessary to permit replication of the published results. Yet there remains in many quarters a sentiment that "only the data are necessary" to permit replication. As long as some economists hold this outdated belief, the profession still needs to accumulate evidence to the contrary. In this issue, more such evidence is provided.

In this issue, Anderson and Delgado ask an interesting question: how easy is it to replicate an empirical paper when you have the correct data? Not at all easy is the unsurprising answer. Along the way, they run into a problem that is familiar when dealing with nonlinear procedures: two packages give two different answers to the same problem.

Let us be clear that the author of the replicated paper, DeSimone, was ready, willing and able to provide replicating code to Anderson and Delgado. They declined to accept it, because possession of said code would have been inconsistent with their research objective. It was particularly gracious of Professor DeSimone, therefore, to handle their queries by phone and email when it would have been much more efficient (from his perspective) simply to say, "Here's the code, stop wasting my time." But he did not do this, and the profession is better off for it.

B.D. McCullough

bdmccullough@drexel.edu 